\title{
Tu P05
}

Customized Injection Monitoring Solution Using PRM Technology

J.E. Lindgard* (Octio AS), S. Bussat (Statoil) \& T. Matveeva (Octio AS)

\section{SUMMARY}

Octio has installed a permanent monitoring system at a waste injection site at the Oseberg field on the Norwegian continental shelf. This system comprises a small ocean-bottom seismic array of 4C stations, designed for both passive monitoring of microseismic events and active seismic surveys (see Lindgård and Matveeva 2013 and Løvheim 2013). The system was designed and installed in a Demo 2000 project supported by the Research Council of Norway and Statoil, and has provided real time data since its installation in 2013. The results from the first year of monitoring show that the system is able to characterize different passive energy sources from sub-hertz up to Nyquist frequency. These passive sources include weak regional earthquakes $(\mathrm{M}<4.5)$ and microseisms from ocean wave oscillation (see Bjerrum et. al., 2014). During the summer 2014 a 4D baseline active survey was successfully conducted. The Oseberg installation is an example where a system is dedicated to injection monitoring over a limited area. The system will provide early warning for caprock integrity issues using passive and microseismic monitoring. 


\section{Introduction}

Octio has installed a permanent monitoring system at a waste injection site at the Oseberg field on the Norwegian continental shelf. This system comprises a small ocean-bottom seismic array of 4C stations, designed for both passive monitoring of microseismic events and active seismic surveys (see Lindgård and Matveeva 2013 and Løvheim 2013). The system was designed and installed in a Demo 2000 project supported by the Research Council of Norway and Statoil, and has provided real time data since its installation in 2013. The results from the first year of monitoring show that the system is able to characterize different passive energy sources from sub-hertz up to Nyquist frequency. These passive sources include weak regional earthquakes $(M<4.5)$ and microseisms from ocean wave oscillation (see Bjerrum et. al., 2014). During the summer 2014 a 4D baseline active survey was successfully conducted.

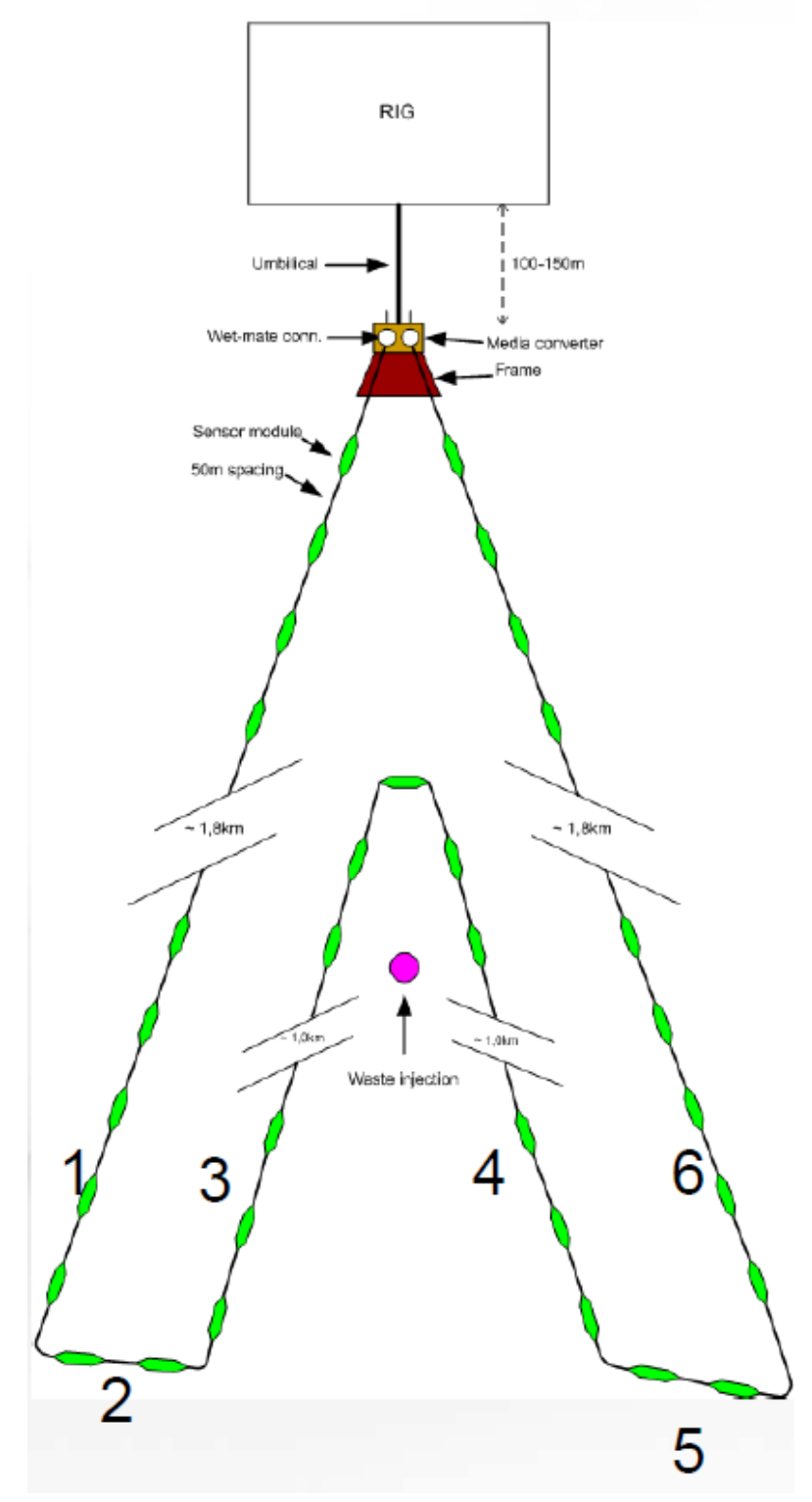

\section{Method and/or Theory}

The objective of the feasibility study was to propose a monitoring system design suitable for active seismic 4D surveys and passive microseismic monitoring of the injection site. The selected design is based on seismic modelling and limited by the rig location and obstructions on the seabed. Despite the limited number of sensors in the layout, modelling showed that system is expected to provide valuable results on caprock integrity and changes in the reservoir.

The Oseberg installation is an example where a system is dedicated to injection monitoring over a limited area. The system will provide early warning for caprock integrity issues using passive and microseismic monitoring.

With time the monitoring need might change due to the increased injection volume and extended lateral injection fluid propagation. The system can then be extended by utilizing a wet-mate connector.

\section{Examples}

Third EAGE Workshop on Permanent Reservoir Monitoring 2014 - Proactive Reservoir Management: PRM and Beyond

Oslo, Norway, 16-19 March 2015 
During the first phase of monitoring no injection was carried out in the dedicated injection well, however activity from nearby production wells were recorded. One example is a perforation shot

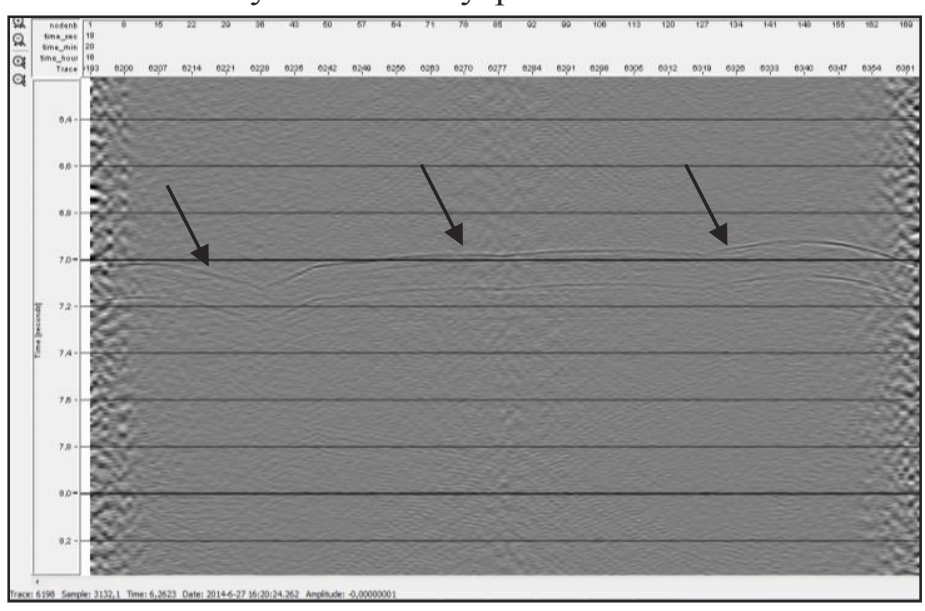
carried out in a well $500 \mathrm{~m}$ west of the PRM system at a depth of $2650 \mathrm{~m}$. The perforation shot contained $0.8 \mathrm{~kg}$ explosives per meter. On the figure above, this perforation shot has been marked with arrows. Notice the clear sea surface multiples following the perforation shot. Only a frequency filter with $15-70 \mathrm{~Hz}$ bandpass has been applied to the data in this image.

\section{Acknowledgements}

We acknowledge Statoil, the Oseberg asset team and Octio for allowing us to present this paper and the Research Council of Norway for supporting the Demo2000 project.

\section{References}

Lindgård, J.E., and Matveeva, T., 2013, Utilizing PRM systems for injection monitoring, EAGE PRM workshop Stavanger, Extended Abstract

Løvheim, L., 2013, Subsea Wireless Technology Improve the Value Proposition for Permanent Reservoir Monitoring, EAGE PRM workshop Stavanger, Extended Abstract

L. Bjerrum, T. Matveeva, J.E. Lindgård, H.I. Rutledal, A.C.S. Yde, 2014, Comparison of noise characteristics on an un-trenched and trenched cable deployed in the north sea for a PRM system,'14 EAGE Conference paper. 